\title{
3X DC-DC Multiplier/Divider for HEV Systems
}

\author{
Wei Qian, Fang Z. Peng, Miaosen Shen \\ Michigan State University, \\ 2120 Engineering Building, \\ East Lansing, MI, 48824
}

\author{
Leon M. Tolbert \\ University of Tennessee, Knoxville, TN \\ Electrical Engineering and Computer Science, \\ Knoxville, Tennessee, 37996
}

\begin{abstract}
This paper presents a bidirectional 3X dc-dc multiplier/divider that can interface the battery with the inverter dc bus for hybrid electric vehicle (HEV) traction drives. Compared with traditional multi-level dc-dc converter, this converter can have three output/input voltage ratios with smooth transition. The control method to limit the transient inrush current, as well as a novel regenerative clamping circuit for multi-level dc-dc converters is provided in this paper. By utilizing the parasitic inductance or the minimum inductance from an air core inductor, the size and weight of the converter can be significantly reduced. Its magnetic-less feature and high efficiency provide the potential of the high temperature operation with the future wide bandgap devices. Experimental results are given to verify the operating principle and the design concepts of this topology.
\end{abstract}

\section{INTRODUCTION}

Power converters play a vital role in Hybrid Electric Vehicle (HEV) systems. Typical HEV drive train consists of a battery, power converter, and a traction motor to drive the vehicle. The power converter could be just a traditional inverter or a dc-dc converter plus an inverter. The latter configuration provides more flexibility and improves the system performance. The dc-dc converter in this system interfaces the battery and the inverter dc bus, which is usually a variable voltage converter so that the inverter can always operate at its optimum operating point. In most commercially available systems, traditional boost converters are used. In this system, the inductor is bulky, heavy, costly, and always one of the hottest components. With the trend of higher coolant temperature of the converters in HEVs, as the only power magnetic component in the system, the dc-dc inductor becomes a major obstacle to further reducing the size, weight, and cost.

Multi-level dc-dc converters become attractive for this application because of the magnetic-less structure. With the development of the wide bandgap device and high temperature multilayer ceramic capacitors, the multi-level dc-dc converters becomes a good candidate for very high temperature operation $\left(>250^{\circ} \mathrm{C}\right)$, which may eliminate coolant and further reduce cost. Traditional multi-level dc-dc converters (switched capacitor converters) usually have fixed input and output voltage ratio. This paper presents a bidirectional $3 \mathrm{X} \mathrm{dc}-\mathrm{dc}$ multiplier/divider that is able to achieve three different output/input voltage ratios by proper control. Thus, the inverter can always operate close to its optimum operation point.

\section{OPERATION PRINCIPLE}

The presented 3X dc-dc multiplier/divider shown in Fig.1 employs the same topology as in literature [1]; however with proper control, it can have three voltage ratios instead of fixed 3:1 shown in [1]. With three different PWM methods, the output voltage ratio Vout/Vin can be 1, 2, or 3 in steady state. Because of its bi-directional nature, the converter can be viewed as a multiplier or a divider based on the definition of source and load.

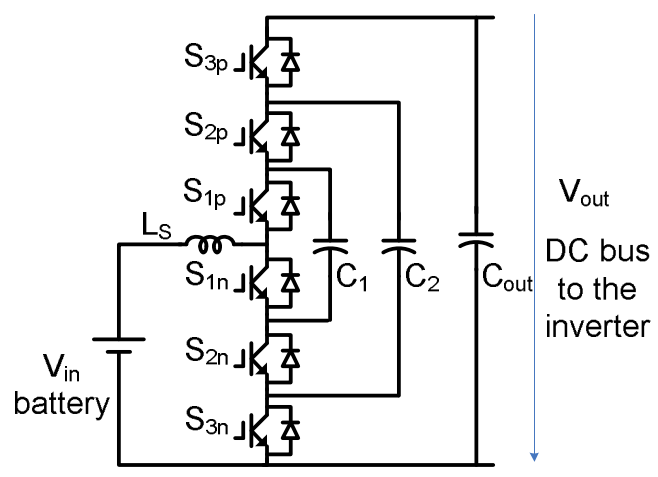

Fig.1. Topology of the $3 \mathrm{X} \mathrm{dc-dc}$ multiplier/divider

1X: To achieve the voltage ratio of 1 , namely $1 \mathrm{X}$, the converter always operates in one switching state as shown in Fig.2, with all the switches (IGBTs with freewheeling diodes) except $S_{1 n}$ always turned on. Thus, all the capacitors are connected in parallel with the input voltage, which ensures the voltage ratio of 1 .

2X: While $\mathrm{C}_{2}$ and $\mathrm{C}_{\text {out }}$ are always paralleled by $\mathrm{S}_{3 \mathrm{p}}$ and $\mathrm{S}_{3 \mathrm{n}}$, the converter alternates with $1 / 2$ duty ratio between two switching states I and II illustrated in Figs.3 (a) and (b). In state I, the capacitor $\mathrm{C}_{1}$ is connected to the battery; in state II, $\mathrm{C}_{1}$ is in series with the battery to connect to $\mathrm{C}_{2}$ and $\mathrm{C}_{\text {out }}$. Consequently, the voltage ratio will be kept to $2 \mathrm{X}$.

$3 \mathrm{X}$ : When the desired ratio is $3 \mathrm{X}$, the converter circulates from switching states I, II to III as shown in Figs.4 (a), (b) and (c), with $1 / 3$ duty ratio per state. In State $\mathrm{I}, \mathrm{V}_{\mathrm{cl}}=\mathrm{V}_{\mathrm{in}}$; in state II, $\mathrm{V}_{\mathrm{c} 2}=\mathrm{V}_{\mathrm{c} 1}+\mathrm{V}_{\mathrm{in}}$; in State III, $\mathrm{V}_{\mathrm{c} 3}=\mathrm{V}_{\mathrm{c} 2}+\mathrm{V}_{\mathrm{in}}$. After these three states, the capacitor voltages will be balanced automatically. As a result, the output voltage is three times the input voltage. 


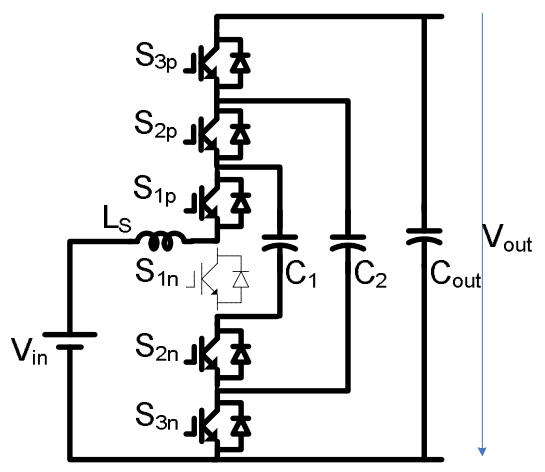

Fig. 2. Switching patterns for $1 \mathrm{X}$ mode

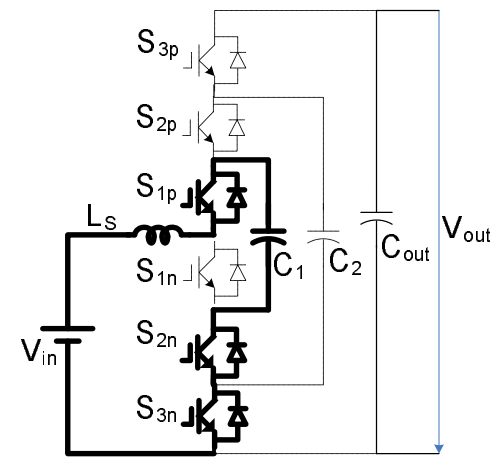

(a)

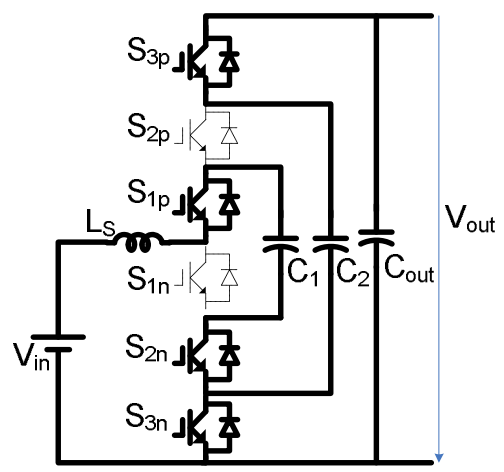

(a)

Fig. 3. Switching patterns for $2 \mathrm{X}$ mode: (a) Switching state I. (b) Switching state II.

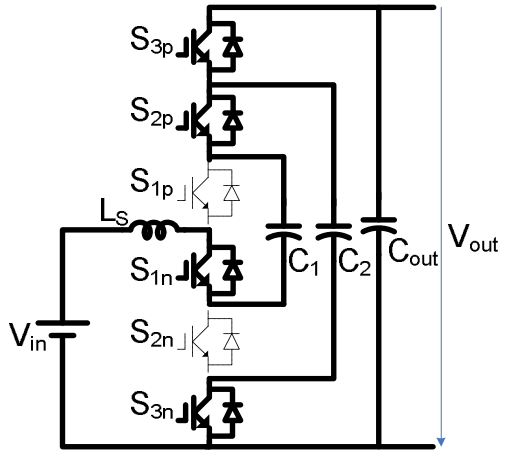

(b)

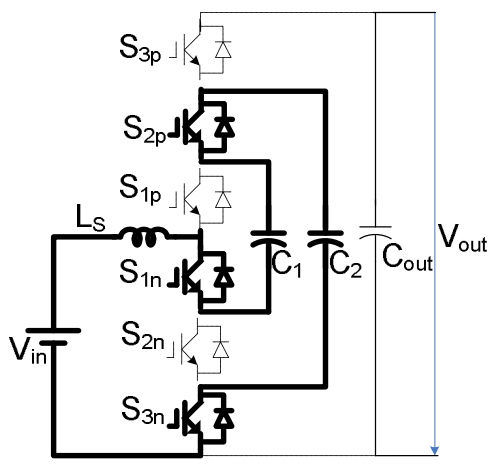

(b)

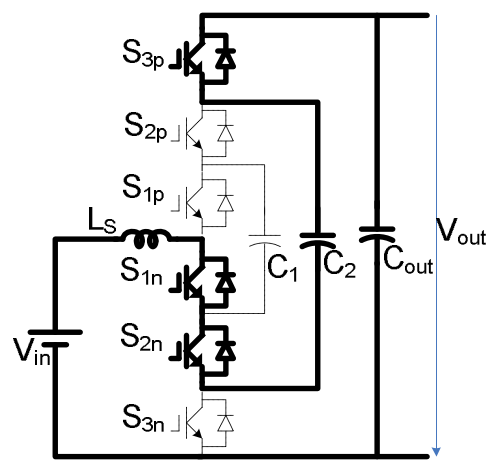

(c)

Fig.4. Switching patterns for $3 X$ mode. (a) Switching state I. (b) Switching state II. (c) Switching state III.

\section{TransiEnt CURRENT CONTROL DURING Transition}

In the steady state, the capacitor voltages are well balanced and the voltage differences are very small, so the current through the switches is relatively small. However, during the transition when the output voltage ratio changes between $V_{\text {in }}$ and $2 V_{\text {in }}$, or between $2 V_{\text {in }}$ and $3 V_{\text {in }}$, the voltage differences are very large, which can lead to high transient current through the devices and capacitors. Therefore, a variable PWM duty ratio and high switching frequency is indispensable in transition in order to limit the transient current. Furthermore, a small air-core inductor can be added when parasitic inductance is not enough for the large voltage difference and the adopted devices can not achieve sufficiently high switching frequency.

\section{A. Changing the output voltage from $1 V_{\text {in }}$ to $2 V_{\text {in }}$}

Before changing the output voltage from $1 \mathrm{~V}_{\text {in }}$ to $2 \mathrm{~V}_{\mathrm{in}}$, all the three capacitors are initially charged to $1 \mathrm{~V}_{\text {in }}$ in $1 \mathrm{X}$ mode. After the transition, the capacitors $\mathrm{C}_{2}$ and $\mathrm{C}_{\text {out }}$ should be charged up to $2 \mathrm{~V}_{\mathrm{in}}$. Assume that the aforementioned inductor current is continuous and define duty ratio $\mathrm{D}$ as of the time when $\mathrm{C}_{\text {out }}$ is charged by the addition of $\mathrm{C}_{1}$ and the battery over the entire switching period $\mathrm{T}_{\mathrm{s}}$. There are two active switching states and one freewheeling state between them. In the active switching states, the gate signals are given in sequence to the switches as shown in Figs. 3(a) and (b) of the 2X steady state operation, except that the duty ratio $\mathrm{D}$ increases gradually. To balance the voltage across $C_{1}$, the duty ratios of the two switching states I and II are assigned equal. In the freewheeling state shown in Fig. 5, the switches $S_{2 p}, S_{1 p}, S_{1 n}$ and $S_{2 n}$ are all given the turn-off gate signals, therefore, the continuous current goes through the freewheeling diodes inside $S_{1 p}$ and $S_{2 p}$. So the middle point voltage $V_{m}$ equals $V_{o}$ for a duration of $(1 / 2-\mathrm{D}) \mathrm{T}_{\mathrm{s}}$ after each active state. According to the inductor voltage-second balance in steady state, the relationship of the input voltage with output voltage and duty cycle is:

$$
V_{\text {in }}=D V_{c 1}+D\left(V_{\text {out }}-V_{c 1}\right)+2\left(\frac{1}{2}-D\right) V_{\text {out }}=(1-D) V_{\text {out }}
$$

From the steady state boundary condition of $1 \mathrm{X}$ and $2 \mathrm{X}$ modes, the duty cycle should vary from 0 to $1 / 2$ to change the output smoothly to $2 \mathrm{~V}_{\text {in }}$. The PWM signals are shown in Fig. 6.

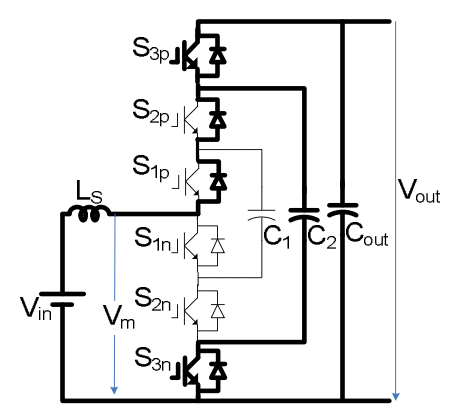

Fig. 5. The freewheeling state in the $1 \mathrm{X}$ to $2 \mathrm{X}$ transition 


\section{$S_{3 p}, S_{3 n}$ \\ $\mathrm{S}_{2 \mathrm{p}}, \mathrm{S}_{1 \mathrm{n}} \mathrm{\perp}$

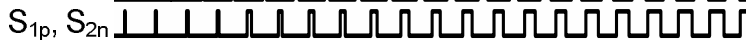

Fig.6. PWM signals during the transition from $1 \mathrm{X}$ to $2 \mathrm{X}$

B. Changing the output voltage from $2 V_{\text {in }}$ to $3 V_{\text {in }}$

Applying the same principle to the transition from $2 \mathrm{~V}_{\text {in }}$ to $3 \mathrm{~V}_{\text {in }}$, there are three active switching states and three freewheeling states shown in Fig. 7 among them. The duration is $\mathrm{DT}_{\mathrm{s}}$ for each active state and $(1 / 3-\mathrm{D}) \mathrm{T}_{\mathrm{s}}$ for each freewheeling state. In the active switching states, the PWM signals in Fig. 8 are given to the corresponding switches as shown in Figs. 4(a), (b) and (c) of the 3X steady state operation. In the freewheeling state shown in Fig. 7(a), since only $S_{3 n}$ is kept on after State I in Fig. 4(a), the continuous current freewheels through the diodes inside $S_{1 p}$ and $S_{2 p}$ and thereby $\mathrm{V}_{\mathrm{m}}$ equals $\mathrm{V}_{\mathrm{c} 2}$; in Fig. 7 (b), $\mathrm{V}_{\mathrm{m}}$ equals $\mathrm{V}_{\text {out }}-\mathrm{V}_{\mathrm{c} 1}$ due to the freewheeling; in Fig. 7(c), $\mathrm{V}_{\mathrm{m}}$ equals $\mathrm{V}_{\mathrm{out}}-\mathrm{V}_{\mathrm{c} 2}+\mathrm{V}_{\mathrm{c} 1}$. Hence, the relationship of the input and output voltages can be derived as:

$$
V_{\text {in }}=\left(\frac{2}{3}-D\right) V_{\text {out }}
$$

From the boundary condition, the ideal duty cycle varies from $1 / 6$ to $1 / 3$ in the transition.

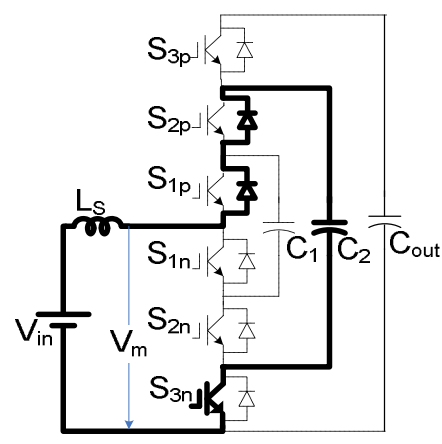

(a)

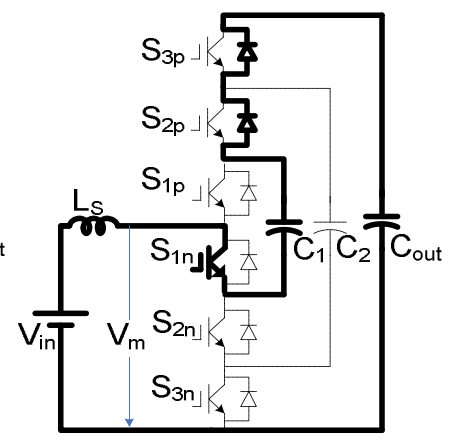

(b)

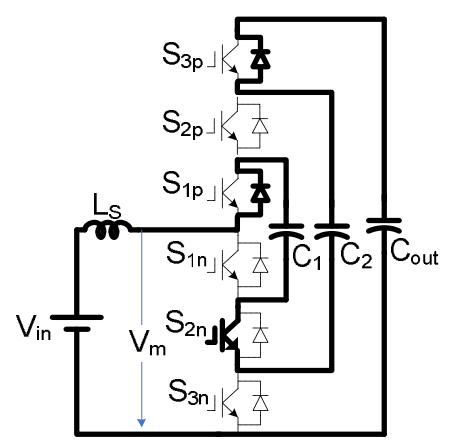

(c)

Fig. 7. The freewheeling states in the $2 X$ to $3 X$ transition: (a) Freewheeling after the active switching state I in Fig. 4(a). (b) Freewheeling after the active switching state II in Fig. 4(b). (c) Freewheeling after the active switching state III in Fig. 4(c)

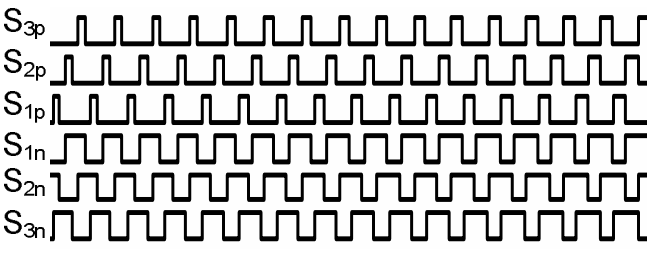

Fig.8. PWM signals during the transition from $2 \mathrm{X}$ to $3 \mathrm{X}$

C. Changing the output voltage from $3 V_{\text {in }}$ to $2 V_{\text {in }}$

The control strategy for the $3 V_{\text {in }}$ to $2 V_{\text {in }}$ transition is to maintain the first two switching patterns in $3 \mathrm{X}$ mode as shown in Figs. 4 (a) and (b) for $1 / 2$ duty ratio. After the output capacitor $\mathrm{C}_{\text {out }}$ is naturally discharged by the load and its voltage goes down to below the voltage of $\mathrm{C}_{2}$, there will be no oscillation when $S_{3 p}$ is switched on as shown in Fig. 8. In consequence, the converter settles down to the $2 \mathrm{X}$ mode bidirectional steady state operation as shown in Figs. 3 (a) and (b).

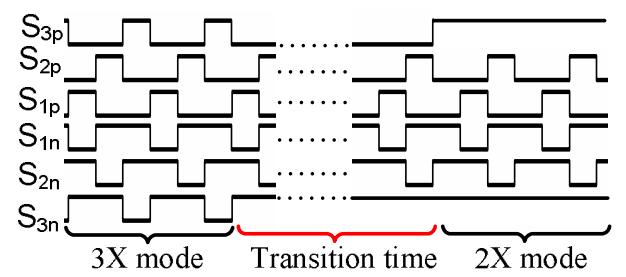

Fig.9. PWM signals during the transition from $3 \mathrm{X}$ to $2 \mathrm{X}$

D. Changing the output voltage from $2 V_{\text {in }}$ to $1 V_{\text {in }}$

Similarly, during the transition from $2 \mathrm{X}$ to $1 \mathrm{X}$, the switching state of the converter is the same as the switching state shown in Fig. 4(a). That is, the gate signals illustrated in Fig. 10 are applied to only keep $S_{1 p}, S_{2 n}$ and $S_{3 n}$ on. After the three capacitor voltages turn to equal, $S_{3 p}$ and $S_{2 p}$ will be turned on so that the converter can smoothly transfer to the $1 \mathrm{X}$ mode steady state operation in Fig. 2.

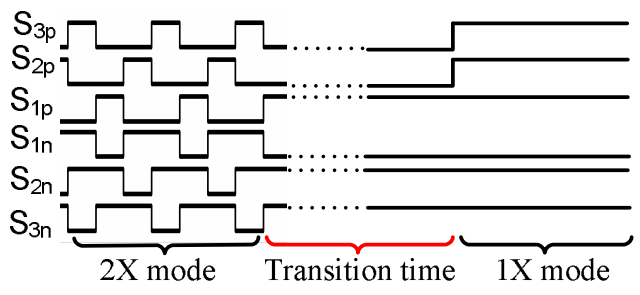

Fig.10. PWM signals during the transition from $2 \mathrm{X}$ to $1 \mathrm{X}$

\section{Clamping Circuit}

One of the challenges for the multi-level dc-dc converters in high power application is the high frequency spikes during the diode reverse recovery. They add significant stress and additional losses to the device, and also bring in EMI problems to the system. Therefore, a RCD clamping circuit as shown in Fig. 11 is proposed for this multilevel dc-dc topology. The basic principle is the same as that of the traditional RCD clamping circuit. When the switch is turned off, the current will be first diverted into the clamping 
capacitor through the clamping diode. Then the clamping capacitor regenerates the energy back to the main capacitor through a resistor, as can be seen from the energy feedback loop for the clamping capacitors $\mathrm{C}_{1 \mathrm{p}}$ and $\mathrm{C}_{1 \mathrm{n}}$. However, the other clamping cells in Fig. 11 make use of the switching devices in the main circuit to create the discharge loop. For instance, in Fig. 12(a), when the freewheeling diode in the switch $S_{2 n}$ turns off, the stray energy from the diode reverse recovery will flow into the clamping capacitor $\mathrm{C}_{2 \mathrm{n}}$. When the switch $S_{2 n}$ is on, the stored energy will be fed back to $C_{1}$ through resistor $R_{2 n}$ and diode $D_{d 2 n}$. Such diodes in the discharge loop as $\mathrm{D}_{\mathrm{d} 2 \mathrm{n}}$ are added to guarantee the unidirectional current. In the same way, the clamping capacitor $C_{3 n}$ will get a chance to recover energy back to $C_{1}$ when the switches $S_{2 n}$ and $S_{3 n}$ are both conducting. It is noteworthy that in the boost mode operation, the actual conducting devices are the upper three freewheeling diodes in $S_{x p}$ and the lower three IGBTs in $S_{x n}(x=1,2,3)$, and vice versa in the buck mode operation. Nevertheless, the discharge current can still pass through either the IGBT or its freewheeling diode as any of them is carrying the load current.

The discharge loop for the clamping capacitor $\mathrm{C}_{3 \mathrm{p}}$ behaves in the same fashion, but there are two discharging states for $\mathrm{C}_{3 \mathrm{p}}$ as shown in Figs. 12(b) and (c). In the 1/3 switching period in Fig. 12(b), when the switches $S_{2 p}$ and $S_{3 n}$ are on, the captured energy in $C_{3 p}$ will flow to $C_{\text {out }}$ through $C_{2}, R_{3 p}$ and $D_{\mathrm{d} 3 \mathrm{p}}$. In another $1 / 3$ period in Fig. 12(c), the energy in $\mathrm{C}_{\mathrm{s} 3 \mathrm{p}}$ will flow to $C_{2}$ through $C_{1}, R_{3 p}$ and $D_{d 3 p}$, when the switches $\mathrm{S}_{3 \mathrm{p}}$ and $\mathrm{S}_{2 \mathrm{n}}$ are on.

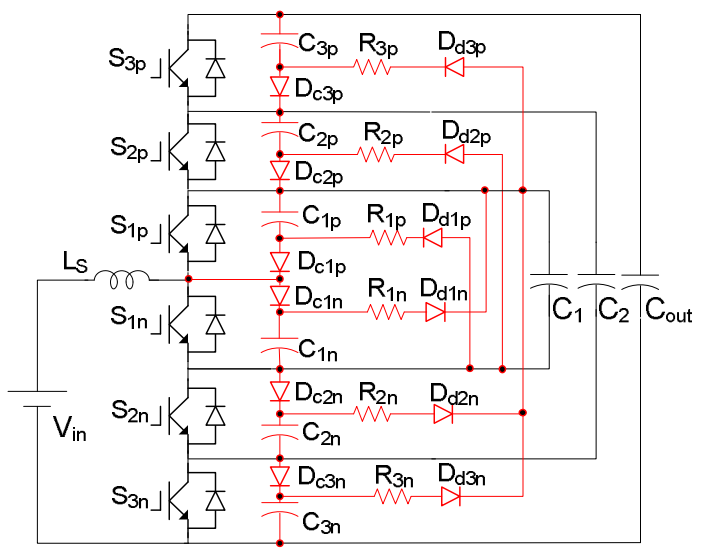

Fig.11. The clamping circuit

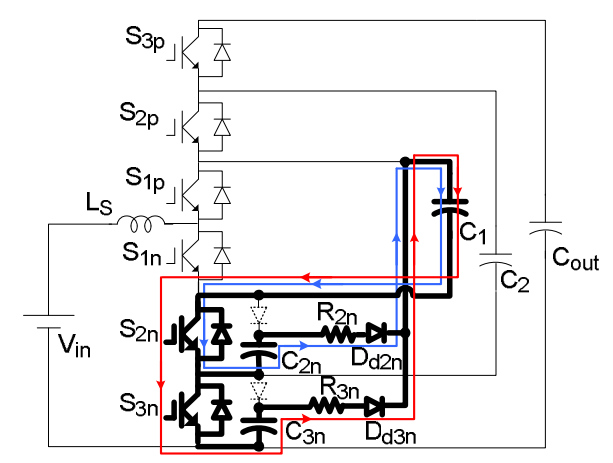

(a)

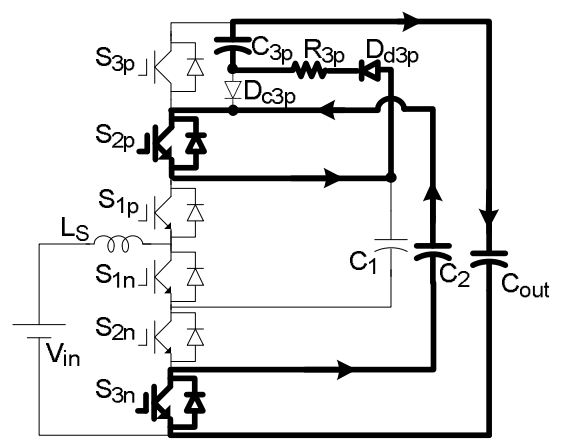

(b)

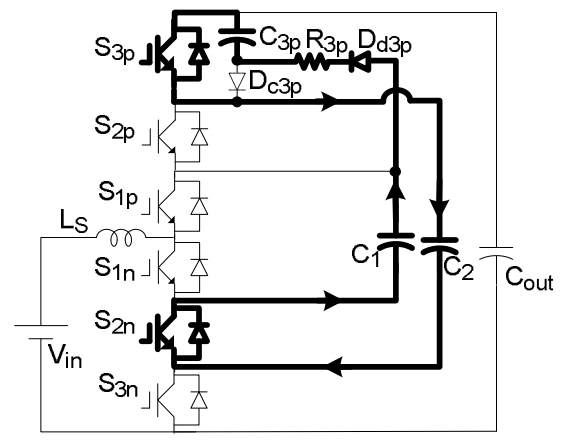

(c)

Fig.12. Typical discharge loops: (a) The discharge loop for $S_{2 n}$ and $S_{3 n}$. (b) The discharging state I for $S_{3 p}$. (c) The discharging state II for $S_{3 p}$.

\section{EXPERIMENTAL RESULTS}

A $55 \mathrm{~kW}$ prototype was built to verify the functionality. Fig.14 shows the final assembly based on the 3-D design in Fig. 13. The dimension is $27.2 \times 24.4 \times 8.8 \mathrm{~cm}^{3}$ and its weight is around $5.6 \mathrm{~kg}$. The switches used are integrated in an IPM module PM600CLA600. The capacitors for $\mathrm{C}_{1}$ and $\mathrm{C}_{2}$ are $500 \mu \mathrm{F}$ and $240 \mu \mathrm{F}$ film capacitors respectively. The output capacitor consists of $40 \mathrm{uF}$ film capacitors from the $3 \mathrm{X} \mathrm{dc}-\mathrm{dc}$ converter and an $820 \mathrm{uF}$ capacitor bank that is to mimic the $\mathrm{dc}$ link capacitor shared between the dc-dc converter and the subsequent inverter. A $5 \mathrm{uH}$ inductor is used in the experiment. In the hybrid electric vehicles, it is reasonable to take the advantage of the parasitic inductance in the battery and in the cable connecting the converter to the battery. In some hybrid electric vehicles, the battery is located about $2 \sim 3$ meters away from the converter. The converter operates at $8 \mathrm{kHz}$ in $3 \mathrm{X}$ mode and $12 \mathrm{kHz}$ in $2 \mathrm{X}$ mode in steady state and it works at $20 \mathrm{kHz}$ during the transition to limit the inrush current. The complex logic for duty ratio and frequency control in steady state and transient operation is implemented by one CPLD chip XC95288XL.

Fig. 15 shows the waveforms in the steady state operation. A buck/boost converter switching at $1 \mathrm{kHz}$ is used to as an electronic load. Fig. 15(a) shows the input/output voltage and current waveforms in $3 \mathrm{X}$ mode at the $55 \mathrm{~kW}$ peak power. Figs. 15 (b) and (c) are the corresponding waveforms in $2 \mathrm{X}$ and $1 \mathrm{X}$ modes at their $30 \mathrm{~kW}$ peak power. The output/input voltage ratio is lower than $\mathrm{nX}$ because of the device voltage stress and dead time as discussed in [4]. Fig.16 shows the converter 
performance during voltage ratio change transition, in which the converter is loaded with a $30 \mathrm{Ohm}$ resistor bank. As can be seen, in all cases the transient current is well limited. Fig. 17 shows the measured efficiency at different output power in $\mathrm{nX}$ mode. The overall efficiency in the $30 \mathrm{~kW}$ continuous power range is over $97 \%$.

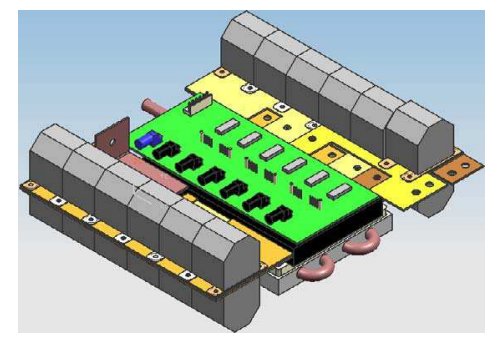

Fig. 13. 3-D design

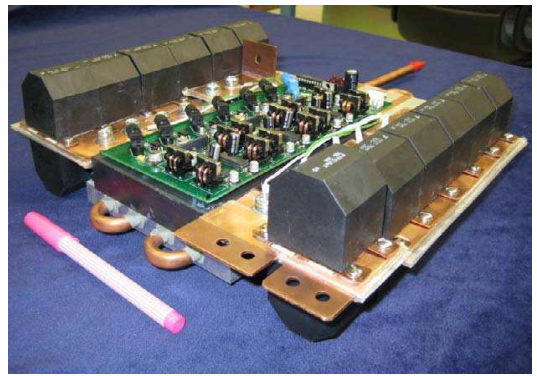

Fig. 14. The $55 \mathrm{~kW}$ dc-dc prototype

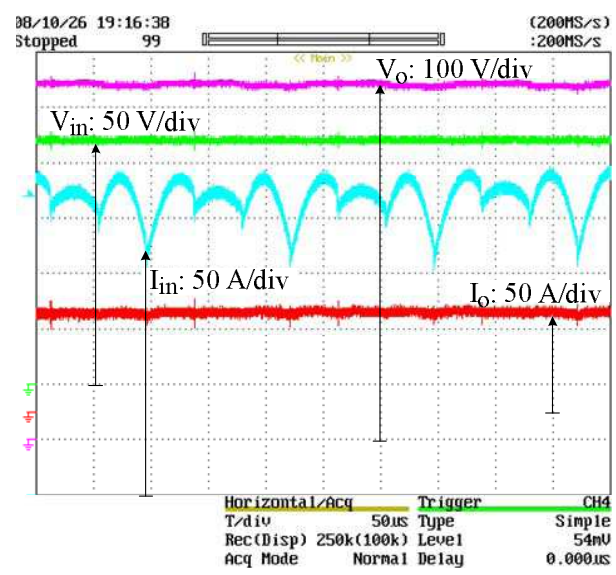

(a)

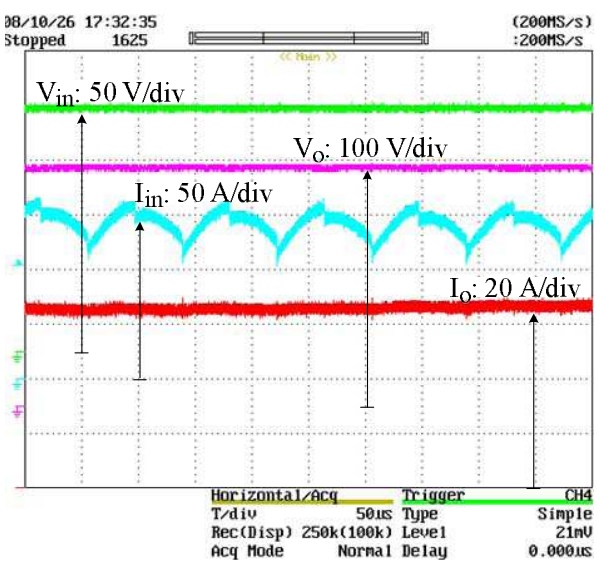

(b)

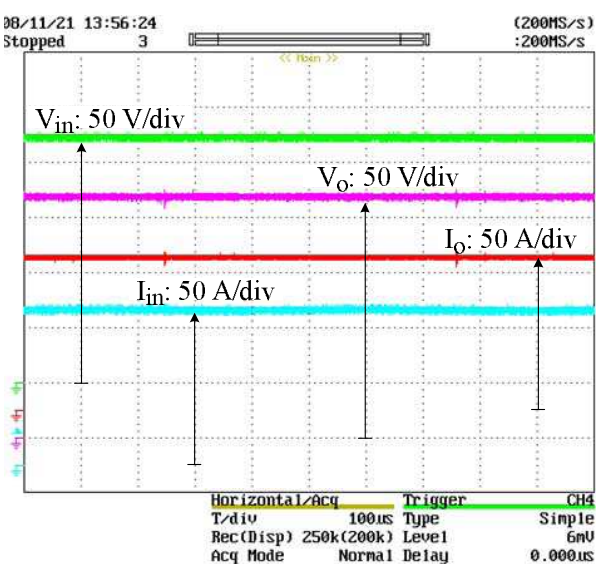

(c)

Fig. 15. Waveforms in steady state operation: (a) $3 \mathrm{X}$ boost mode at $55 \mathrm{~kW}$ output. (b) $2 \mathrm{X}$ boost mode at $30 \mathrm{~kW}$ output. (c) $1 \mathrm{X}$ boost mode at $30 \mathrm{~kW}$ output
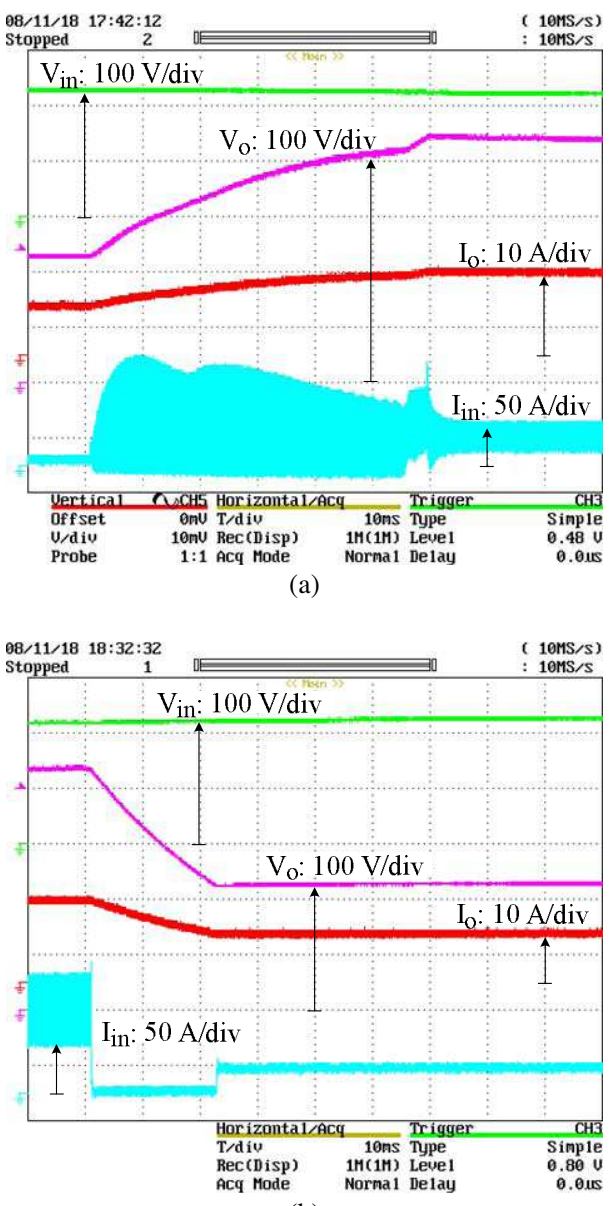

(b) 


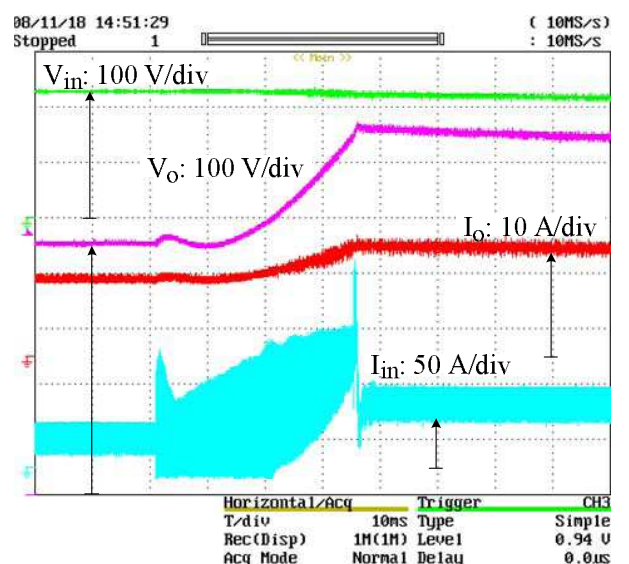

(c)

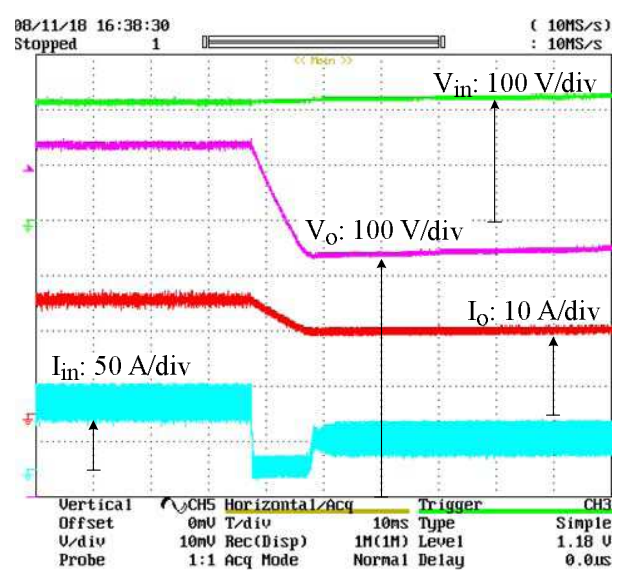

(d)

Fig. 16. Waveforms of the $\mathrm{nX}$ mode transition: (a) Transition from $1 \mathrm{X}$ to $2 \mathrm{X}$ (b) Transition from $2 X$ to $1 X$. (c) Transition from $2 X$ to $3 X$. (d) Transition from $3 \mathrm{X}$ to $2 \mathrm{X}$

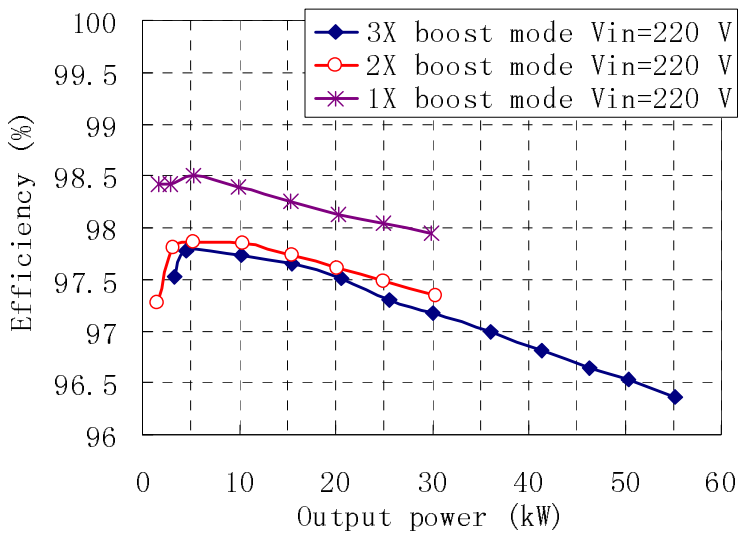

Fig.17. Efficiency of the $55 \mathrm{~kW}$ prototype

Compared with the conventional switched capacitor converters, the $3 \mathrm{X}$ multiplier/divider realizes three output/input voltage ratios by minimum number of capacitors and switching devices with the lowest voltage stresses. By the combination of three output voltage ratios in the dc-dc converter and the continuous adjustment of the modulation index, the inverter can operate in its high efficiency region. The dc-dc converter can be made more compact by using customized capacitors and heat sink. There is still great potential to make it even lighter by replacing the film capacitors with multilayer ceramic capacitors (MLCC), as nowadays some medium-voltage MLCCs already have several tens of microfarad capacitance and comparable ampere ripple current capability.

\section{CONCLUSION}

A $3 \mathrm{X}$ dc-dc multiplier/divider with three variable output/input voltage ratios is presented in this paper. The transient current is well under control with the help of the duty ratio variation and switching frequency control. The proposed principle of the clamping circuit can serve as an example of addressing the high frequency spikes in multi-level converters. The experimental results of a $55 \mathrm{~kW}$ prototype in steady state and transient operation validate the operating principle. The efficiency testing results demonstrate its potential for high temperature HEV systems.

\section{REFERENCES}

[1] F. Z. Peng, F. Zhang, Z. Qian, "A novel compact dc-dc converter for 42V systems," IEEE Power Electronics Specialists Conference, pp. 3338, June 2003.

[2] F. Zhang, F. Z. Peng, Z. Qian, "study of multilevel converters in dc-dc application," IEEE Power Electronics Specialists Conference, pp. 17021706, June 2004.

[3] Z. Pan, F. Zhang, and F. Z. Peng, "Power losses and efficiency analysis of multilevel DC-DC converters," in Proc. IEEE Appl. Power Electron. Conf., Mar. 2005, pp. 1393-1398

[4] M. Shen; F. Z. Peng; L. M. Tolbert, "Multilevel dc-dc power conversion system with multiple dc sources", IEEE Transactions on Power Electronics, vol. 23, no. 1, pp. 420-426, Jan 2008.

[5] F. L. Luo and H. Ye, "Positive output multiple-lift push-pull switched capacitor Luo-converter," IEEE Trans. Ind. Electron., vol. 51, no. 3, pp. 594-602, Jun. 2004.

[6] K. K. Law, K. W. E. Cheng, and Y. P. B. Yeung, "Design and analysis of switched-capacitor-based step-up resonant converters,” IEEE Trans. Circuits Syst. I, vol. 52, no. 5, pp. 943 - 948, May 2005.

[7] F. H. Khan, L. M. Tolbert, "Universal multilevel dc-dc converter with variable conversion ratio, high compactness factor and limited isolation feature", in Proc. IEEE Appl. Power Electron. Conf., Feb, 2008, pp. 1723.

[8] B. Arntzen and D. Marksimovic, "Switched capacitor dc-dc converters with resonant gate drive," IEEE Trans. Power Electron., vol. 13, no. 5, pp. 892-902, Sep. 1998.

[9] W. Harris and K. Ngo, "Power switched-capacitor dc-dc converter, analysis, and design," IEEE Trans. Aerosp. Electron. Syst., vol. 33, no. 2, pp. 386-395, Apr. 1997. 